\title{
Utilization of Bamboo Shoots (Bambusa vulgaris) in Chips Production
}

\author{
Dolly P. Maroma \\ College of Industrial Technology, Bulacan State University, Bulacan, Philippines \\ Email: maromadolly@ymail.com
}

Received 23 April 2015; accepted 10 May 2015; published 15 May 2015

Copyright (C) 2015 by author and OALib.

This work is licensed under the Creative Commons Attribution International License (CC BY). http://creativecommons.org/licenses/by/4.0/

(c) (i) Open Access

\section{Abstract}

The study aimed to develop bamboo shoots as a healthy snack alternative. Healthy snacks can be an important part of nutritious diet. A healthy snack can offer health benefits. Modern research finds that the bamboo shoot has a number of medicinal benefits, from cancer prevention and weight loss to improving appetite and digestion. Bamboo shoots are not only delicious but also rich in nutrients, and rank among the five most popular healthcare foods in the world. The main raw material used in this study is bamboo shoots locally known as "labong" which is rich in dietary fiber and various vitamins like $\mathrm{C}, \mathrm{E}$, and $\mathrm{B} 6$ as well as nutritious substances and minerals. With the idea of making healthy veggie chips, the researchers decided to make a snack from bamboo shoots or "labong". The product has undergone microbiological analysis and sensory evaluation to determine the safety and acceptability of the product at the Bulacan State University Food Analytical Testing Center. Based on the microbiological analysis of the BSU (Bulacan State University) Analytical Testing Laboratory conducted for the bamboo shoots "labong" chips, the sample has coliform count, yeast and molds count, aerobic plate counts and Staphylococcus aureus count values that are within BFAD standards. The sample passed the microbiological analysis and is considered safe for human consumption. The overall acceptability of the sample product is like.

\section{Keywords}

Bamboo Shoots, Microbiological, Snacks, Chips, Sensory

Subject Areas: Food Science \& Technology

\section{Introduction}

A healthy snack can offer health benefits. Snacks can even be included in a weight loss plan. Eating a healthy snack allows intake of essential nutrients. Fruits and vegetables add vitamins A and C, both of which are important for immunity, wound healing and teeth and gums. They also offer fiber and fill your stomach for very few 
calories.

Eating junk food can have a significant impact on one's health. Though many people enjoy eating junk food and think it tastes great, the health consequences can be serious, and can range from everything to low energy levels to weight gain and illness. The term "junk food" encompasses a fairly broad category of food, but it typically refers to foods that are relatively high in caloric content, but low in nutritional value. Junk food is often high in sugar, salt, white flour, and fat, particularly saturated fat. It is often heavily processed and prepackaged, making it easy to prepare and consume. In addition, eating junk food can cause one to develop insulin resistance, which is one of the risk factors for diabetes. This is a particular concern in children.

Potato chips are one of the common chips that are available in the market. There are many choices and options that can satisfy human's desire for crunchy and appetizing snack, but also provide important nutrients in place of all the fat and salt. In looking for an alternative to potato chips which are one of the popular snacks in the country, veggie chips and fruit chips will be great options. Veggie and fruit chips are healthy in comparison to regular chips, but are low in neither fat nor calories; some of the vegetables used to make veggie chips include sweet potatoes, carrots, yams, beets and taro roots, and for fruit chips include banana, mango and jack fruit.

Modern research finds that the bamboo shoot has a number of medicinal benefits. The health benefits of bamboo shoots include healthy weight loss, control of bad cholesterol, strengthening of the immune system, possible cancer-fighting properties and anti-inflammatory properties. It is heart-friendly, contains protein, a sufficient supply of vitamins and minerals and a negligible amount of fat. It also contains significant amount of dietary fiber.

Bamboo shoots are definitely the portion of bamboo which is not just edible; however it is extremely rich with nourishing components; as a result, they have several positive results within the overall health. Bamboo is part of the grass family. Bamboo shoots are generally younger, new canes which are collected for food just before they are a couple weeks old or even one-foot taller. Bamboo shoots are generally crisp and also sensitive, similar to asparagus, having a taste much like corn. They're utilized regularly in Asian cuisine. In a commercial sense canned bamboo shoots are typical, yet fresh, locally developed bamboo has got much better taste as well as structure.

Bamboo shoots add texture and flavour to the dish and are a good source of soluble and insoluble fiber. One cup contains a scant 14 calories and fat of half a gram. Bamboo shoots are also a good source of potassium, phytochemicals, and phenolic acid, a potent antioxidant [1].

Due to the consumers' demand for quality nutritious food and healthier alternative to traditional chips, the researcher opted to develop a product using bamboo shoots.

With the idea of making veggie chips, the researcher decided to conduct a research study on how to formulate a product from bamboo shoots "labong" to utilize the potential of its nutritional benefits. It can be a healthy alternative to current commercial snacks in the market. Because of its high fiber content it can help people with digestive problems. Lastly, for the children who do not like vegetables and always eat junk foods, this would be a good way for them to eat vegetables without knowing it.

\section{General Objective}

The aimed of this study is to utilized Bamboo shoots "labong" in making a healthy snack chips.

\section{Specific Objectives}

1. To determine the ingredients and processes needed in the production of Bamboo Shoots "Labong" Chips.

2. To determine the microbiological qualities of Bamboo Shoots "Labong" Chips in terms of;

2.1. aerobic plate count;

2.2. coliform count;

2.3. yeast and Molds counts; and

2.4. staphylococcusaureus count.

3. To determine the sensory qualities of Bamboo Shoots "Labong" Chips in terms of;

3.1. color;

3.2. odor;

3.3. taste;

3.4. texture; and 
3.5. after taste.

\section{Methods and Techniques of the Study}

This study used the experimental method with laboratory works in conducting the study. The researchers performed a series of experiments in order to come up with a better output. The researchers gathered information through research materials and study the chosen raw material and how it will be utilized for chips production.

\section{Research Procedure}

The following are the steps in the production of Bamboo Shoot (Labong) Chips.

Selection and Preparation of Raw Materials. The researchers looked for Bamboo shoots that are 7 - 15 days old. The freshly harvested bamboo shoots are washed, and sanitized, after which, 2 - 3 layers of husk as well as the hardened base are removed. The other ingredients were purchased from selected supermarket which sell high quality products.

Sanitation. Prior to the production of Bamboo shoots "Labong" Chips, the researchers prepared and soaked all the tools and equipments to be used into 3 litres chlorine solution for 5 minutes and air dried overnight, and the whole working area is also cleaned and sanitized. To prevent human contamination, the researcher wore proper laboratory attire (laboratory gown, hair net, face mask, and hand gloves) and followed Current Good Manufacturing Procedures (cGMP).

Production of Bamboo Shoots (Labong) Chips. The newly harvested bamboo shoots (Figure 1) were washed and scrubbed then sanitized in chlorinated water for one hour.Sanitizing is a procedure to treat foodcontact surfaces that destroys most disease producing bacteria and viruses, substantially reduces the number of other undesirable organisms, and does not adversely affect the product or its safety for the consumer. Sanitizing can be done with heat or with chemicals. The most commonly used sanitizers in food applications are chlorine gas, sodium or calcium hypochlorite, and organic chlorine (Sodium Dichloroisocyanurate) [2]. After which, 2 3 layers of husk as well as the hardened base are removed and sanitized in chlorinated water for 30 minutes and washed thoroughly. The bamboo shoots were cut into half, separated each sheaths from one another and washed thoroughly. Then it was boiled in two (2) litres of purified water for one (1) hour. After boiling it was drained and blanch to stop the continuous cooking of the shoots. Then it was cut into $50 \mathrm{~mm} \times 250 \mathrm{~mm}$ strips and coated it with cornstarch. Lastly, the coated bamboo strips was deep fried in a 150 Celcius palm oil until golden brown.

After the preparation of the product (Figure 2) it was brought to the BSU-DOST (Bulacan State University

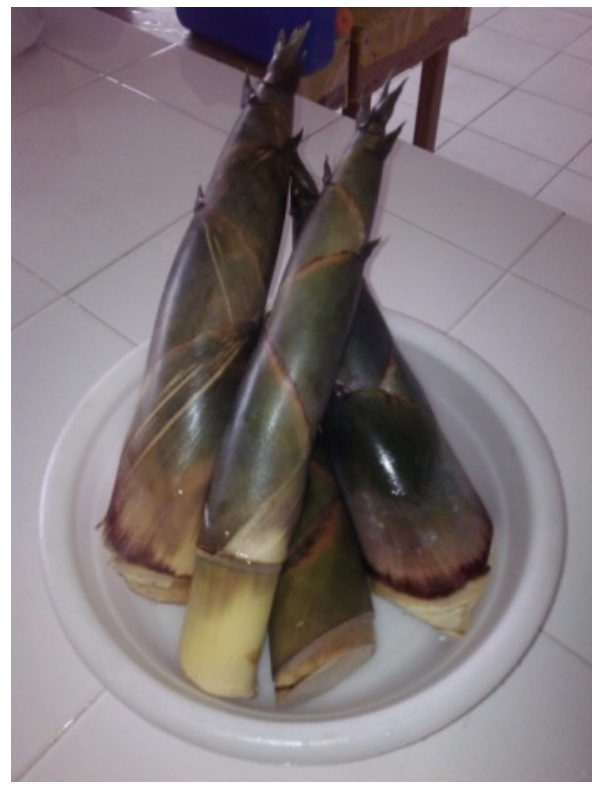

Figure 1. The raw material bamboo shoots. 


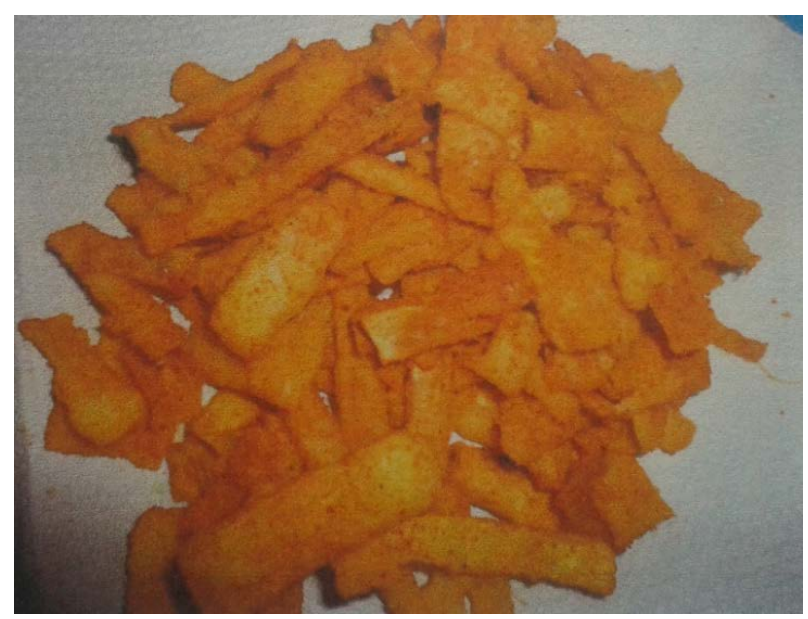

Figure 2. Finished product bamboo shoots “labong” chips.

Department of Science and Technology) Food Testing Laboratory following the protocol for microbiological analyses in terms of Coliform Count, Yeast and Molds Counts, Aerobic Plate Counts, and its Staphylococcus aureus.

Microbiological analysis involves the determination of the microorganisms present in a sample and their quantity in the sample. Food microbiological analysis is conducted to determine the safety and quality of food [3].

The sensory evaluation was also conducted to determine the color, aroma, flavour, texture, salty taste, audible crispiness, aftertaste, and overall acceptability. These were tested among 20 trained panellists against a score sheets designed by the staff of the Bulacan State University and Department of Science and Technology (BSU-DOST) Analytical Testing Laboratory.

Presentation, Analysis and Interpretation of Data. The bamboo shoots "labong chips" was developed using young and fresh bamboo shoots, cornstarch and palm oil. The process involved in the preparation were sanitizing, boiling, blanching, dredging and frying.

Microbiological Properties of Bamboo Shoots "Labong” Chips. The sample was subjected for microbiological analysis in terms of Aerobic Plate Count, Coliform Count, Yeast and Molds Count and Staphylococcus aureus conducted by BSU Analytical Testing Laboratory.

As presented on Table 1, the Aerobic plate count of the product has actual value of less than $10^{4} \mathrm{cfus} / \mathrm{g}$ sample, Coliform count has actual value of less than 10 cfus/g sample, Yeast and molds count of less than $10 \mathrm{cfus} / \mathrm{g}$ sample, and Staphylococcus aureus with the actual value of less than $10 \mathrm{cfu} / \mathrm{g}$ sample. As stated on the interpretation of the result conducted at the BSU-DOST Food Testing Laboratory, the sample has Aerobic Plate Count, Coliform Count, Yeast and Molds Count, and Staphylococcus aureus values that are within the BFAD Microbiological Standards. The sample has passed all the parameters of microbiological quality. Consequently, the product is considered safe for human consumption. The techniques and procedure applied were sufficient enough to control microbiological contamination and prevent the growth of most organisms.

Sensory Properties of Bamboo Shoots "Labong” Chips. Sensory analysis (or sensory evaluation) is a scientific discipline that applies principles of experimental design and statistical analysis to the use of human senses (sight, smell, taste, touch and hearing) for the purposes of evaluating consumer products [4]. The sensory evaluation was conducted by twenty (20) trained and professional panellists from BSU-DOST Food Testing Laboratory. Based on the result of the sensory evaluation conducted, on a 5-point scale that determines the sensory attributes of the sample the above results were achieved.

As presented on Table 2, the color of the product is 2.6 which means light brown, the aroma is 3.0 and it is distinct to the product, same as the flavour which got a score of 2.56. The texture is 3.1 which mean it is crisp and light while the salty taste is 1.4 which means barely perceptible. The audible crispness got a score of 3.56 which mans perceptible. The aftertaste got a score of 1.4 which means non-existent and the overall acceptability of the product has the score of 2.1 which means that he panellist like the product. As stated on the interpretation 
Table 1. Result of microbiological analysis of bamboo shoots "labong” chips.

\begin{tabular}{clcc}
\hline Types of Test & Actual Value & BFAD Standard Value & Result \\
\hline Arobic plate count & Less than $10^{4} \mathrm{cfu} / \mathrm{g}$ & $2 \times 10^{5} \mathrm{cfu} / \mathrm{g}$ & Passed \\
Coliform count & Less than $10^{4} \mathrm{cfu} / \mathrm{g}$ & $10^{2} \mathrm{cfu} / \mathrm{g}$ & Passed \\
Yeast and molds count & Less than $10^{4} \mathrm{cfu} / \mathrm{g}$ & $10^{2} \mathrm{cfu} / \mathrm{g}$ & Passed \\
Staphylococcus aureus & Less than $10^{4} \mathrm{cfu} / \mathrm{g}$ & $10^{2} \mathrm{cfu} / \mathrm{g}$ & Passed \\
\hline
\end{tabular}

Table 2. Result of sensory analysis of bamboo shoot (labong) chips.

\begin{tabular}{ccc}
\hline Sensory Attribute & Score Using 5-Point Scale & Result \\
\hline Color & 2.6 & Light brown \\
Labong aroma & 3.0 & Distinct \\
Labong flavor & 2.56 & Distinct \\
Texture & 3.1 & Crisp and light \\
Salty Taste & 1.4 & Barely perceptible \\
Audible crispness (thru the sense of hearing) & 3.56 & Perceptible \\
Aftertaste (unpleasant) & 1.4 & Non-existent \\
Overall acceptability & 2.1 & Like \\
\hline
\end{tabular}

of the result conducted at the BSU Analytical Testing Laboratory. Based on the result of the sensory evaluation conducted, on a 5-point scale that determines the sensory attributes of the sample the above results were achieved. The results are based on the evaluation conducted among 20 trained panellists.

\section{Summary of Findings}

From the analysis of data presented in this study, the following results were obtained.

1) The bamboo shoots "labong" chips were made out of young bamboo shoots, preferably two weeks old, cornstarch and palm oil.

2) Based on the microbiological analysis of the Bulacan State University Analytical Testing Laboratory conducted for the bamboo shoots "labong" chips, the sample has coliform count, yeast and molds count, aerobic plate counts and Staphylococcus aureus count values that are within BFAD standards. The sample passed the microbiological analysis, the finding revealed that Aerobic plate count has an actual value of less than $10^{4} \mathrm{cfus} / \mathrm{g}$ sample, the Coliform count has an actual value of less than $10 \mathrm{cfus} / \mathrm{g}$ sample, the Yeast and molds count with the actual value of 10 cfus/g sample, and lastly Staphylococcus aureus count has the actual value of less than 10 cfus/g sample. The Bulacan State University Analytical Testing Laboratory concluded that the bamboo shoots "labong" chips are safe for human consumption.

3) Based on the sensory evaluation of BSU Analytical Testing Laboratory using five (5) point scale. The color is 2.6, which is light in color, aroma (fried potato chips) is 3.0 which means distinct, the flavor (fried chips) is 2.56, perceptible, the texture is 3.1 , which means crisp and light, its salty taste with 1.4 is barely perceptible, aftertaste is 1.4 which means non-existent. The overall acceptability received a mean of 2.1 which means that the product is like by the evaluators.

\section{Conclusions}

From the collated results of the study, the following conclusions were determined within the limitations and scope defined in the study.

1) Bamboo shoots are a good source of raw material for chips production.

2) The sample product passed the BFAD standards in terms of microbiological analysis. 
3) The overall acceptability of the product is like by the evaluators.

\section{Recommendation}

In reference to the scope and delimitation, findings and conclusion of the study, the following recommendations are hereby presented.

1) Subsequent microbiological analyses of the sample may be conducted to monitor microbiological quality of sample preferably within a 12-month period to comply with the standards set by the Department of Health.

2) Further experimentations and studies should be conducted to determine shelf-life and nutrient content analyses to complete regulatory requirements on food safety.

3) Further study should be conducted for the application of bamboo shoots in various food products.

4) Determination of appropriate packaging material of the product should be determined to maintain human consumption suitability, product safety and prolong its shelf-life.

\section{References}

[1] Baskette, M. and Painter, J. (2008) The Art of Nutritional Cooking. 3rd Edition, Prentice Hall, New Jersey, 295.

[2] Parker, A. (2007) Effective Cleansing and Sanitation Procedure. University of Maryland and Johnson Diversey Corporation. http://jifsan.umd.edu/pdf/gaqps_en/Section9.Effective_Cleaning_and_Sanitizing_Procedures.pdf

[3] Fratamico, P.M., Bhunia, A. and Smith, J.L. (1997) Foodborne Pathogens: Microbiology and Molecular Biology. Academic Press, Wymondham.

[4] Sensory Analysis. http://en.wikipedia.org/wiki/Sensory_analysis 